\title{
Why Diagnosis of Meniere's Disease is Difficult? Understanding of the Diagnostic Criteria
}

\author{
Hyun Ji Kim and Kyu-Sung Kim \\ Department of Otorhinolaryngology-Head and Neck Surgery, College of Medicine, Inha University, Incheon, Korea
}

\section{메니에르병의 진단은 왜 어려운가? 진단기준의 이해}

김 현 지·김 규 성

인하대학교 의과대학 이비인후-두경부외과학교실

\author{
Received July 10, 2017 \\ Revised September 1, 2017 \\ Accepted September 14, 2017 \\ Address for correspondence \\ Kyu-Sung Kim, MD, PhD \\ Department of Otorhinolaryngology- \\ Head and Neck Surgery, \\ College of of Medicine, \\ Inha University, 27 Inhang-ro, \\ Jung-gu, Incheon 22332, Korea \\ Tel $+82-32-890-3620$ \\ Fax $+82-32-890-3580$ \\ E-mail stedman@inha.ac.kr
}

The Best clinical approaches for Meniere's disease starts from the proper diagnosis which is based on the clinical symptoms, including the characteristic features of vertigo and auditory symptoms. After first criteria has been made in 1972 by the American Academy of Otolaryngology-Head and Neck Surgery, it has been revised two times in 1985 and 1995. Japanese criteria have been made in 1974 and revised 2008. Most recent criteria of the Barany Society has been established in 2015. The basic notion is almost similar among these criteria, but detailed descriptions has been gradually changed in characteristics of vertigo and auditory symptoms based on the updated research data and consensus. Understanding of how the diagnostic criteria of Meniere's disease has been evolved is very important in terms of good clinical practice because they contain the development of knowledge about the disease. This article reviewed all the diagnostic criteria, and compared the differences.

Korean J Otorhinolaryngol-Head Neck Surg 2017;60(11):541-7

Key Words Diagnosis $\cdot$ Endolymphatic hydrops $\cdot$ Meniere's disease $\cdot$ Vertigo.

\section{서 론}

메니에르병은 귀가 평형기능을 가지고 있다는 것이 밝혀지 기 시작한 19 세기부터 이과학 연구의 발전과 역사를 함께 해 온 내이질환이다. 19세기말 프랑스 의사인 메니에르(Prosper Meniere)가 급성 어지럼 및 난청이 내이에서 기원함을 주장 한 이래 1938년 영국의사 홀파이크와 일본의사 야마카와가 내림프수종이 병태생리라고 기술한 이후 많은 연구가 이루어 졌다.2) 1972 년 미국, 1974년 일본에서 진단기준을 제정하고 이후 몇차례의 개정을 통하여 발전시켜 왔고, 최근 바라니학 회(Barany Society)에서 새로운 진단기준을 정하였다. ${ }^{3-6)}$ 메니에르병은 이처럼 규정된 진단기준이 있고, 이를 근거로

This is an Open Access article distributed under the terms of the Creative Commons Attribution Non-Commercial License (http://creativecommons.org/licenses/by-nc/4.0) which permits unrestricted non-commercial use, distribution, and reproduction in any medium, provided the original work is properly cited.
진단을 내림에도 불구하고 임상의가 진료를 볼 때 메니에르 병의 진단을 내리기가 쉽지만은 않다. 그 이유는 메니에르병 의 병인과 병태생리가 ‘원인미상의 내림프수종'이며 검사로 이를 입증할 객관적 진단방법이 없다는 점, 귀에서 발생될 수 있는 전정 및 와우증상을 망라하는 증후군성 발현을 보 이고 이것이 시차를 두고 점진적으로 나타날 수 있다는 점, 그 리고 기타 내이질환과 감별이 필요하다는 점 때문이다. 이러 한 진단의 혼동은 내이질환의 진료경험이 길지 않은 임상의사 일수록 더할 것으로 생각한다.

메니에르병은 반복성 어지럼과 함께 난청, 이명, 이충만감으 로 증상을 정의하지만, 임상에서 경험하는 환자의 증상발현 은 다양하다. ${ }^{2)}$ 초기 발작 시 어지럼 또는 청각증상이 부분적 으로 발현될 수 있고, 어지럼의 양상, 지속시간, 난청의 양상, 발생시점, 어지럼과 청각증상의 시간적 관계가 매우 다양하게 나타나기 때문에, 메니에르병의 진단과 감별진단에 있어 고 
민에 빠지기 쉽다. 임상의사가 이러한 진료상 혼동을 적극적 으로 극복할 수 있는 방법으로 저자가 제안하는 것은, 우선 그간 수많은 연구결과에 근거하여 발전해 온 메니에르병의 진단기준을 숙지하는 것, 그 진단기준의 개정이 이루어져 온 학문적 이유와 배경을 이해하는 것, 그리고 전정편두통 등 공 통유병률이 높은 것으로 보이는 감별대상 질환에 대한 이해 를 높이는 것이다. 그러나 이와 같이 질병의 역사적 측면까지 각자 직접 공부하는 데는 많은 노력과 시간이 소요되는 바, 저 자는 이에 도움이 되고자 그간 진화해 온 메니에르병의 진단 기준을 증상을 중심으로 정리하고자 한다.

\section{본 론}

\section{메니에르병의 개념과 진단기준의 발전 경과}

메니에르병의 최초 진단기준은 1972년에 만들어졌다. ${ }^{3)}$ 그 이전 1860년 Meniere ${ }^{7)}$ 의 보고 이후 1867 년 Politzer ${ }^{8}$ 가 유사 한 증례를 모아 'Symptom der Meniereschen Krankeitform' 이라는 용어를 사용한 이래, 반복성 어지럼을 보이는 질환명 으로 'Meniere's disease, Meniere's symptom complex, morbus Meniere, pseudo-Meniere's disease, atypical Meniere's disease, Meniere's disorder, Meniere's attack' 등의 다양한 명 칭이 특별한 정의 없이 사용되었다. ${ }^{2)}$ 진단기준의 혼란은 연구 에 혼동을 일으키고 학문적 발전을 저해한다. 이에 미국 안. 이비인후과학회에서 진단기준을 제정하였고, 이후 1985년과 1995년 두 차례에 걸쳐 개정하였다. ${ }^{3,4,6)}$ 일본의 경우 1974년에 후생노동성의 주도로 진단기준이 만들어지고, 2008년 개정되 었으며, 일본어지럼평형의학회 차원에서는 1987년에 만든 바 있다. 2) 2015년에 바라니학회의 전정질환에 대한 국제적 분류 를 위한 위원회에서 개정된 진단기준을 제안하였다. ${ }^{5)}$

\section{미국 이비인후과학회 진단기준}

1972년 제정된 미국이비인후과학회의 진단기준"은 '단일 한 진단기준의 필요성'에 의하여 만들어졌다. 그 이전까지 전 세계적으로 명확한 진단기준이나 확진적 검사방법이 없는 상태에서도 Furstenberg 식이요법, ${ }^{9)}$ 전정신경절제술(Dandy, 1912년), 다양한 내림프낭감압술식(Portmann G 1927년, Naito 1952년, House 1962년) 등 ${ }^{10-12)}$ 의 치료들이 이루어졌으며, 이 치료효과 및 예후를 판정하는 데 있어 질환의 정의와 진단기 준이 중요한 요소로 부각되었다. 여기서 결정된 요소를 요약 하면, 질환의 정의로서 발작적인 어지럼과 청력 소실 및 이명 을 특징으로 하며, 병리학적으로는 내림프수종과 연관된 막 미로의 질환으로 규정한 것, 병명에 있어 'Meniere's disease' 이외 다른 유사명칭은 사용하지 않기로 한 것, 와우 메니에르
병과 전정 메니에르병이라는 아형(subtype) 명칭을 사용하도 록 정한 것, 치료효과의 보고 기준을 정한 것 등이 있다.

1985년에 개정된 진단기준 ${ }^{6}$ 은 객관성(objectivity)과 명확 성(clarification)을 목표로 개정되었다. 그 이유는, 이전 기준에 서 정한 메니에르병의 아형으로 인하여 난청과 어지럼을 보이 는 대부분의 내이질환이 메니에르병의 진단기준에 포함되어 버린다는 점과, 반복성 어지럼만 보이는 전정 메니에르병이 와 우증상을 포함한 전형적 메니에르병으로 진행되는 비율이 낮 다는 누적된 연구결과 때문이다. 이 기준에서는 발병 원인으 로서 ‘원인미상' 이외에는 진단기준에 포함되지 않게 하여 감 별진단의 중요성을 강조하고, 치료효과의 보고 기준을 정량 화, 세분화하였다.

미국의 기준으로는, 현재까지 최종본으로 가장 널리 사용되 는 1995년의 기준은 단순화(simplification)하면서 포용성 (flexibility)을 목적으로 이루어졌다. 그 이유는 85년도에 개 정한 경직된 기준으로 인하여 초기에 전형적인 증상이 나타나 지 않는 환자군에 대한 관리 및 추적에 있어 어려움을 겪게 되었기 때문이다. 이에 '진단단계 staging'이라는 개념이 도입 되어, 증상발현에 따라 'certain, definite, possible, probable' 의 네 단계로 만들었다(Table 1).

\section{일본 후생노동성 및 어지럼평형의학회의 진단기준}

특정 희귀질환 극복을 목표로 한 일본 정부의 주도 하에 메 니에르병 조사연구반이 활동하여 1974년에 처음으로 진단기 준을 만들었다. 메니에르병의 주요 증상요소로, 1) 회전성 어 지럼이 반복할 것, 2) 이명, 난청 등 와우증상이 변동, 반복할 것, 3) 중추성을 포함한 다른 원인이 배제될 것 등의 3 가지를 정하고, 이를 모두 충족할 경우에는 확실례, 1), 2) 또는 1), 3)

Table 1. Diagnostic criteria of Meniere's disease of the American Academy of Otolaryngology-Head and Neck Foundation, United States in $1995^{4)}$

확실한(certain) 메니에르병
명확한 메니에르병과 병리 조직 소견 확진이 동반
명확한(definite) 메니에르병
2회 이상의 20분 이상 지속되는 자발 현기증의 병력
청력 검사로 기록된 난청이 1 회 이상 존재
동측의 이명이나 이충만감
가능성이 높은(probable) 메니에르병
1회 이상의 확실한 현기증의 병력
청력 검사로 기록된 난청이 1회 이상 존재
이명이나 이충만감
가능성이 있는(possible) 메니에르병
난청을 동반하지 않은 주기적 현기증의 병력
감각신경성 난청, 변동성 혹은 고정성, 평형장애를 동반하지만
확실한 현기증의 병력은 없음


Table 2. 일본 후생노동성 난치성질환극복연구사업 연구조사반 메니 에르병 진단기준(2008) $)^{13)}$

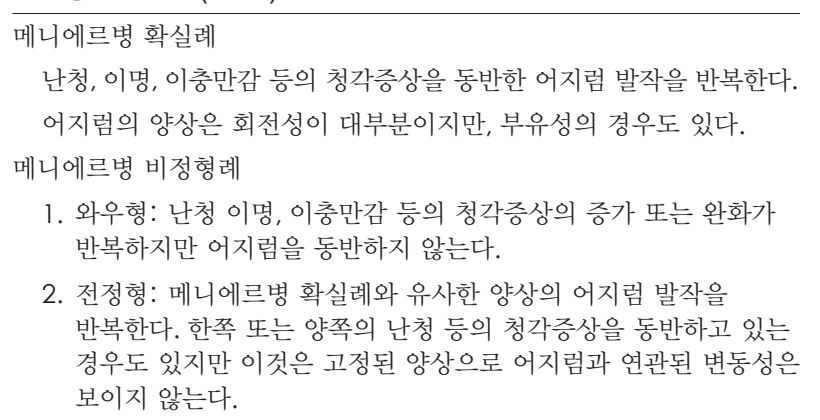

만을 만족하는 경우 의심례로 규정하였다. 이후 조사연구반 의 추가적인 활동으로 2008 년에 개정을 하였는데, ${ }^{13)}$ 세 가지 주요 증상요소는 유지하였고, 어지럼의 양상이 회전성이 아니 라도 난청, 이명, 이충만감의 와우증상이 전형적일 경우 확실 례에 포함하도록 기준을 완화하였다. 또한 메니에르병 의심 례 이외에 비전형례를 정의하여, '와우형'의 경우 청각증상을 전형적으로 보이지만 어지럼이 없는 경우로 정의하였고, '전정 형'의 경우 반복되는 어지럼과 함께 동반되는 청각증상이 변 동, 반복성을 보이지 않고 고정되어 있는 경우로 정의하였다. 즉 이때의 개정에서는 어지럼의 정의를 완화하고, 고정된 난청 을 동반한 반복성 어지럼 환자를 메니에르병의 영역에 포함시 키는 연구결과를 반영하였고(Table 2), 이를 근거로 2011년에 진료가이드라인을 제정하였다. ${ }^{14}$

한편 일본어지럼평형의학회에서는 1987년 학회 차원의 진 단기준을 제안하여, ${ }^{15)}$ 질환 개념은 '원인불명의 내림프수종' 으로 정의하고, 각각 병력, 검사결과 및 종합판정으로 진단을 유도하도록 만들었다. 병력은 1) 반복하는 발작성 회전성 어 지럼, 2) 어지럼 발작에 동반되어 변동하는 와우증상(이명, 난청), 3) 전정·와우신경 이외의 신경학적 증상은 없음, 4) 원인 은 불명이라는 네 가지 조건을 규정하였고, 이를 모두 만족 할 때 메니에르병으로 진단하기로 하였다. 진단을 위한 검사 결과 조건으로, 1) 청력 검사로 메니에르병에 특징적인 난청 을 확인, 2) 평형기능 검사에서 내이장애의 소견을 확인, 3) 신경학적 검사에서 어지럼에 연관된 전정·와우신경 이외의 장애는 없음, 4) 이비인후과적, 내과적, 임상병리학적 검사 등 에서 내이장애의 명확한 원인은 불명함으로 규정하였다. 이 를 통하여 병력의 조건과 검사의 조건을 모두 만족하는 경우 ‘확실례', 병력은 만족하지만 검사에서는 가끔만 만족하거나 항상 음성소견을 보일 때 메니에르병 '거의 확실례'라고 정의 하였다(Table 3). ${ }^{2}$

\section{바라니학회 진단기준}

바리니학회에서는 전정질환에 대한 국제적 분류를 위한 위
Table 3. Diagnositic criteria of Meniere's disease of the Japan Society for Equilibrium Research in $1987^{15)}$

1. 질환개념: 원인불명의 내림프수종

2. 병력으로부터의 진단

1) 반복되는 발작성의 회전성 어지럼

2) 어지럼 발작에 동반되어 변동하는 와우증상(이명, 난청)

3) 제8뇌신경 이외의 신경학적 증상은 없음

4) 원인불명

1), 2), 3), 4)를 모두 만족할 때 메니에르병을 의심

3. 검사로부터의 진단

1) 청력 검사로 메니에르병에 특징적인 난청을 확인

2) 평형기능 검사에서 내이장애의 소견을 확인

3) 신경학적 검사에서 어지럼에 연관된 제8뇌신경 이외의 장애는 없음

4) 이비인후과적, 내과적, 임상병리학적 검사 등에서 내이 장애의 명확한 원인이 불명

4. 종합 판정

1) 메니에르병을 확정하는 경우: 병력에서 메니에르병을 의심하고 검사에서 1 4)를 만족할 때

2) 메니에르병을 대략 확정하는 경우: 병력은 만족하지만 검사에서는 가끔만 만족하거나 항상 음성소견을 보일 때

원회(Classifcation Committee for an International Classification of Vestibular Disorders)를 구성하였다. 바라니학회 는 전정평형계 질환과 관련된 권위있는 전문가그룹으로 구성 된 학회로서, 이비인후과 및 신경과 임상의사를 중심으로 구 성되어 있으며, 위 위원회를 중심으로 합의를 바탕으로 한 다양한 어지럼 질환에 대한 정의 및 진단기준 제정 활동을 하고 있다. 이러한 활동의 일환으로 2015년에 진단기준을 발 표하였고, 이것은 우리나라를 비롯하여 독일, 프랑스, 스페인, 일본, 터키, 이탈리아 등에서 번역발표 되었다.5)

이 위원회는 특히 국제두통학회(International Headache Society)와 공동으로 진행하는 전정편두통(vestibular migraine)에 대한 진단기준을 만들어, 2013년에 개정된 세계두 통학회 진단기준 ICHD-III 의 부록에 전정편두통이 채택되 는 데 큰 기여를 하였다. 따라서 기존 전정편두통과 메니에르 병의 공통유병률에 대한 연구결과를 고려하였을 때, 바라니 학회의 메니에르병 진단기준에 있어 이 부분이 반영된 점을 고려해 볼 필요가 있다. 본 학회의 진단기준에 있어 특징은 기준이 defninte와 probable로 구성되어 있다는 점, 어지럼은 2회 이상 반복성이면서 회전성일 뿐 아니라 부유성(floating) 이나 움직이는 느낌만으로도 어지럼으로 인정하기로 한 점, 청력에 있어서 어지럼 이전, 동안, 이후에 최소 한 번은 저음중음에 걸친 감각신경성 난청이 한쪽 또는 양쪽에 있는 것, 변 동성 청각증상(난청, 이명, 이충만감)이 환측에 있는 것, 그리 고 확실한 감별진단을 하는 것을 조건으로 구성되어 있다. 이 것이 모두 충족되는 경우 'definite', 청각증상의 조건이 확인 되지 않는 경우에는 'probable'로 판정한다. 
Table 4. Diagnostic criteria for Meniere's disease of the Barany Society in $2015^{5}$

1. 명확한 메니에르병(definite Meniere's disease)

1) 자발성 회전성 어지럼이 2 회 이상 발생하고, 발생시간이 20 분에서 12시간까지 지속

2) 한쪽 귀에서 청력 검사로 확인된 저주파에서 중주파수 대역의 감각신경성 난청이 있으며, 이는 어지럼 발작 전, 발작 시 또는 발작 후에 이환된 귀에서 최소 1회 이상 보이는 경우

3) 이환된 귀의 변동성 청각증상들(난청, 이명 또는 이충만감)

4) 다른 전정질환의 배제

2. 가능성 높은 메니에르병(probable Meniere's disease)

1) 20 분 24 시간 지속되는 자발성 어지럼 또는 어지럼이 2회 이상 발생

2) 이환된 귀의 변동성 청각증상들(청력, 이명 또는 이충만감)

3) 다른 전정질환의 감별

바라니학회의 기준은 구성과 정의에서 기존 미국, 일본의 진단기준과 크게 다르지는 않지만, 어지럼 발작의 인정범위 에 운동감도 포함시켜 확대하였고, 어지럼의 지속시간에 있 어 상한선을 두어 전정편두통과 감별을 위한 기준의 차별성 강화를 시도하였다는 점이 중요한 부분이며, 이에 대하여 아래 다시 설명한다(Table 4).

\section{메니에르병 진단기준의 요소와 그 변화에 대한 이해}

\section{어지럼}

메니에르병의 어지럼 발작은 전통적으로 내림프수종과 그 에 따른 막파열설(membrane rupture theory), ${ }^{16)}$ 칼륨독성가 설(potassium intoxication theory) ${ }^{17)}$ 에 근거한 전정성 어지 럼으로, 전형적으로 빙빙 도는 듯한 회전감으로 정의한다. 그 러나 위 가설이 입증된 바가 없고, 실제 임상에서 어지럼의 양상은 객관화가 불가능하여 환자의 주관적 느낌과 표현력 에 의존할 수밖에 없어 한계가 있다. 임상적으로 명확한 메니 에르병으로 판단되는 환자에서 회전감보다는 부유감, 운동감 으로 호소하는 경우가 많아, 이를 메니에르병의 어지럼이 아니 라고 부정하기 어렵다.

일본의 1974년도 기준과 미국의 1972년, 1985년 및 1995년 진단기준에서는 '메니에르병의 어지럼은 회전성'이라고 규정 하였으나, 2008년에 개정된 일본 후생노동성의 진단기준의 본문에서는 '메니에르병의 어지럼은 회전성인 경우가 많지만 비회전성인 경우도 있다'라고 확대하였고, 2015년 바라니학회 의 기준에도 회전성이 아닌 운동감이 메니에르병 어지럼의 범 위에 포함되었다. 즉, 현재 가장 널리 사용되는 1995년 미국 이비인후과학회의 진단기준상 어지럼의 정의인 'attacks of a spinning sensation'을 기준으로 보았을 때, 이후 일본의 기준 도 비회전성 어지럼을 포함하고, 바라니 기준도 어지럼의 정의 를 회전성 이외의 감각 즉, 원문을 이용하면 "the sensation of self-motion when no self-motion is occurring or the sensation of distorted self-motion during an otherwise normal head movement', 움직이는 듯한 느낌, 좌우, 상하 움직임 등 의 비회전성 감각을 모두 포함하기로 한 것을 고려하였을 때 전반적으로는 어지럼 양상에 있어 더 엄격하지 않게 인정하 려는 경향이 있다는 것을 알 수 있다. 따라서 우리는 진료 시 이를 고려하여 메니에르병의 진단에 적용할 필요가 있다.

어지럼 발작의 지속시간에 있어서, 미국 기준은 20 분 이상 이라는 하한선을 명확히 두고 있으며, 상한선에 있어서는 본 문에 '통상적으로 24시간을 넘지 않는다'고 기술하고 있고, 이는 최초부터 1995년도 개정 기준까지 유지되고 있다. 일본 의 2008년도 기준에서는 '10분에서 수십 분 정도'로 광범위 하게 표현하고 있으나, 반면 '수초에서 수십 초의 짧은 어지럼 은 메니에르병이 아니다라고 명확히 부정하고 있다. 한편 바 라니학회의 진단기준에서 어지럼의 지속시간은 20 분에서 12 시간이라고 상한 및 하한선을 모두 명확히 제시하고 있고, 지 속시간이 12시간을 넘어 24시간 이내로 지속되는 경우 "probable로 구분하고 있다. 기존 미국과 일본의 기준에서 어지럼 의 최소 지속시간을 제시한 것은 양성발작성두위현훈, 신경혈 관압박증후군(neurovascular compression syndrome) 등과 같이 어지럼의 지속시간이 짧은 반복성 어지럼 질환과 구별 을 명확하게 하기 위한 것이지만, 상한선에 있어서는 명확한 기준을 정하지 않고 본문에 ‘통상 24시간을 넘지 않는다'라 는 정도로 기술한 반면, 바라니학회의 진단기준은 이를 12시 간으로 엄격히 정한 것이 큰 차이이다. 이는 두통의 지속시간 이 4 시간에서 72 시간 정도로 긴 편두통의 진단기준과 구분 을 명확히 하기 위한 것으로, 2013년에 개정된 세계두통학회 진단기준 ICHD-III 의 부록(appendix)에 전정편두통이 새 로운 진단기준에 포함된 것과 관련이 있으며, 이는 약 $50 \%$ 까 지 보고되는 메니에르병과 편두통의 높은 공통유병률은 향 후 두 질환의 연구와 분석에 큰 장애요인이기 때문이다.

그러나 임상의사의 입장에서 어지럼의 양상처럼 지속시간 도 전적으로 환자의 기억과 진술에 의존할 수밖에 없고, 발 작기가 지난 직후 남은 어지럼의 잔여감 및 체위성 어지럼을 어지럼 지속시간에 포함시켜 진술하는 환자가 많다는 점을 고려하면 진단에 많은 어려움을 겪을 수밖에 없다. 이를 극 복하기 위하여 병력청취를 할 때, 1) 회전감을 느낀 지속시간, 2) 어지럼과 동반되는 구토, 구역감을 느낀 시간, 3) 어지럼으 로 인하여 일상생활을 중단된 시간 등으로 구분하여 각각을 명확히 진술하게 함으로써 어지럼 지속시간의 보다 정확한 추정이 가능하다. 반면, 어지럼이 회전감뿐 아니라 부유감까 지 완화된 것을 고려하면 지속시간의 병력청취는 더 어려워 진 것이고, 따라서 병력청취에 보다 세밀함이 요구된다. 또한 
일과성허혈의 진단기준상 신경학적 증상의 지속시간이 24시 간 이내인 점을 고려하면 메니에르병의 진단기준(미국 기준 및 바라니학회의 probable 기준)과 감별을 위한 임상적 고려 가 필수적이다.

\section{청각증상}

메니에르병에 있어 청각증상은 두 가지 측면에서 중요하다. 첫 번째는 메니에르병의 이환측을 구별해 내는 열쇠의 역할 을 한다. 방향변환성 양상을 보이는 안진이나 전정기능 검사 는 이환측을 결정하는 데 도움이 되지 않기 때문이다. 두 번 째는 메니에르병에서 현재까지는 유일한 객관적 검사소견을 제공한다. 미국의 진단기준상 전정기능 검사는 보조적 역할 일 뿐 진단의 필수요소가 아니고, 바라니학회 및 일본 후생 노동성 진단기준도 마찬가지이다. 검사소견을 진단기준에 포 함시킨 일본어지럼평형의학회 기준상에서도 전정기능 검사 는 청력 검사, 신경학적 검사, 내과적 검사 등 네 종류의 검사 항목 중에 포함된 것으로써, 신경학적 검사나 내과적 검사가 감별진단을 위한 검사이고, 청력 검사를 통한 난청의 확인은 필수라는 것을 고려할 때 전정기능 검사상 내이장애 소견의 여부가 진단에 영향을 미치지 않는다. 따라서 메니에르병이 내이질환으로 청각 및 전정 증상을 모두 나타내어도 순음청 력 검사로 확인된 난청의 객관적 소견이 가장 큰 중요성을 갖는다고 할 수 있다.

난청의 양상에 있어서, 미국 진단기준에서는 '청력 검사로 확인되는 난청'이 확인되더라도 이것이 꼭 변동성일 필요 없 이 고정성 난청도 인정되는 반면, 바라니 기준은 일측성 저주 파에서 중주파장애형 감각신경성 난청과 변동성 난청을 모 두 포함하여 조건이 엄격해졌고, 난청이 있어도 이 조건을 못 맞추면 'probable'에 포함되도록 되어 있다. 한편 일본 정부의
1974년 진단기준에서는 '초기 저주파를 중심으로 변동성 난청 이 있으나 병이 진행되면서 중·고주파 영역도 난청이 발생되 면서 변동성이 없어진다라고 구체적으로 기술되어 있다. 일 본 학회의 기준에서는 '특징적으로 저주파 난청이 발생하지만 어지럼과 함께 변동하는 감각신경성 난청에서 후미로성 난청 이 아닌 것이 확인되면 이러한 조건이 아니라도 메니에르병 의 난청으로 인정한다'고 기술되어 있다.

난청과 어지럼의 발현에 대한 시간적 관계에 대하여, 미국 기준은 청력의 변동성과 함께 시간적 일치성도 조건에 포함 되어 있지 않은 반면, 바라니학회 기준은 어지럼의 이전, 동 안, 이후에 이환 측에 난청이 발생될 수 있다고 모든 경우의 수를 포함한 조건으로 기준을 만들었고, '어지럼 발작 이전 수개월에서 수년 전부터 청각증상만 나타날 수 있고, 어지럼 발작이 동시에 나타나는 경우도 있고 그렇지 않은 경우도 있 다고 광범위하게 인정하고 있다. 일본의 학회 기준에서는 어 지럼과 ‘동시에' 변동하는 청각증상이 생긴다고 규정하고 있 고, 일본 정부 기준에 근거한 2011년 진단 가이드라인에서는 '청각증상은 어지럼 발작 이전 또는 발작과 동시에 생기고 악 화되었다가 어지럼 완화와 함께 호전된다'고 기술되어 있다. 즉, 모든 진단기준에서 어지럼과 난청의 시간적 관계는 진단 기준에 포함되어 있지 않고, 단지 임상의사의 이해를 돕기 위 한 설명 정도로 기술되어 있을 뿐이다. 대부분의 환자가 어지 럼 발작 수시간 내지 수일 전, 또는 발작 중에 청각증상을 느 끼는 반면 난청이 발생된 후 수년에서 수십 년 이후에 어지럼 이 발생되는 지연성 내림프수종이나, 미리 생긴 난청이 어지럼 발작과 동시에 급격히 소실되는 Lermoyez 증후군 등의 비 특이적 발현례가 있다는 점을 고려해야 한다. ${ }^{18)}$ 어지럼 발작 에 의해 심리적 공황상태에 이르는 일부 환자에서는 난청 발 생의 전후관계를 전혀 기억하지 못하여 병력청취에 실패하는

Table 5. Comparison of three diagnostic criteria of definite Meniere's disease based on the cochlear and vestibular symptoms

\begin{tabular}{|c|c|c|c|}
\hline 지표 & 미국 이비인후-두경부외과학회(1995 $)^{4)}$ & $\begin{array}{c}\text { 일본어지럼평형의학회(1987) } \\
\left(^{15)}\right. \\
(\text { 일본 후생노동성 연구반, 2008) }\end{array}$ & 바라니학회(2015) $)^{5)}$ \\
\hline \multicolumn{4}{|l|}{ 어지럼 } \\
\hline 양상 & $\begin{array}{l}\text { 회전성 } \\
\text { 2회 이상 재발성 }\end{array}$ & $\begin{array}{l}\text { 회전성(비회전성 포함) } \\
\text { 2회 이상 재발성 }\end{array}$ & $\begin{array}{l}\text { 회전성, 비회전감 포함 } \\
\text { 2회 이상 재발성 }\end{array}$ \\
\hline 지속시간 & 20분 이상(통상적 24시간 이내) & $\begin{array}{l}\text { 10분 수십 분(수초 수십 초는 } \\
\text { 명확히 배제) }\end{array}$ & $\begin{array}{l}\text { 20분 12시간(12 24시간은 } \\
\text { probable) }\end{array}$ \\
\hline \multicolumn{4}{|l|}{ 난청 } \\
\hline 정의 & $\begin{array}{l}\text { 청력 검사로 확인된 난청 } \\
\text { 변동성이 확인될 필요 없음 }\end{array}$ & $\begin{array}{l}\text { 어지럼이 동반된 난청 및 이명 } \\
\text { 저주파 또는 수평형 감각신경성 } \\
\text { 변동성 포함 }\end{array}$ & $\begin{array}{l}\text { 저음형 또는 중주파 감각신경성 } \\
\text { 변동성 포함 }\end{array}$ \\
\hline $\begin{array}{l}\text { 어지럼과 } \\
\text { 시간적 관계 }\end{array}$ & 시간적 일치성 불포함 & 어지럼 발작 이전 또는 동시에 발생 & $\begin{array}{l}\text { 어지럼의 이전, 동안, 이후에 발생 } \\
\text { (수개월 수년) }\end{array}$ \\
\hline 기타 & $\begin{array}{l}\text { 해당 귀의 이명 또는 이충만감 } \\
\text { 다른 전정질환 배제 }\end{array}$ & $\begin{array}{l}\text { 이충만감은 불포함 } \\
\text { 8번 뇌신경 이외의신경학적 } \\
\text { 증상 배제 }\end{array}$ & $\begin{array}{l}\text { 이명 또는 이충만감은 난청과 함께 } \\
\text { ‘변동성 귀증상’으로 포함 } \\
\text { 중추성 및 기타원인 배제 }\end{array}$ \\
\hline
\end{tabular}


경우도 있어 진단에 어려움을 겪지만, 이런 경우는 다시 재 발하는 경우에 파악이 가능하다.

메니에르병의 증상으로 어지럼, 난청과 함께 이명과 이충 만감을 각각 별도의 증상으로 구분하는 경우도 있고, 실제로 나눠서 호소하는 환자도 있지만, 미국과 바라니학회의 진단 기준 모두 이명과 이충만감을 각각의 조건이 아니고 '또는'의 조건으로 기술하고 있다. 이는 구별이 명확하지 않은 경우가 많을 뿐 아니라, 난청과 달리 객관적으로 측정할 수 없는 증 상이기 때문이다. 일본 학회 기준의 경우 와우증상(난청, 이명) 으로 표현하고 이충만감에 대해서는 별도로 표현하고 있지 않다(Table 5).

\section{결 론}

내림프수종을 병태생리로 하는 메니에르병의 진단은 현재 까지 임상적 기준에 근거한다. 그러나 어지럼, 난청, 이명, 이 충만감 등 증상발현의 시간차, 병력청취의 어려움과 증상의 재발성 발현, 그리고 귀에서 발생될 수 있는 대부분의 증상 이 포함되어 있어 감별진단에 주의가 필요하다는 점 등으로 인하여 메니에르병의 확진에 어려움을 겪는다. 동시에 메니 에르병의 특성상 초기 발현에 모든 증상을 보이지 않을 수 있다는 점을 고려하여 진료 시점에 진단기준을 충족하지 않 더라도 메니에르병일 가능성을 염두에 두고 추적관찰하는, 보다 열린 진단적 접근 자세가 필요하다. 특히, 진단적 접근 수단이 제한되어 있고, 아직까지 병태생리의 불명확성이 많 은 내이질환의 진료에 있어서 이러한 자세는 특히 중요하다고 생각한다. 이러한 어려움을 해결하는 방안으로 저자가 제시 하고자 하는 것은, 우선 메니에르병 진단기준의 발전을 충분 히 숙지하여 전정, 청각증상의 특성을 잘 이해하는 것과, 재 발성 어지럼을 보이는 다른 전정질환에 대한 지식을 넓혀 감 별진단에 대한 자신감을 높이는 것이다. 저자는 이를 위하여 그간 발전과 변화를 해 온 국제적 또는 개별 국가의 진단기 준 내용 및 배경과 전정, 청각증상 특성을 중심으로 정리하 였다.

\section{Acknowledgments}

This research was supported by Basic Science Research Program through the National Research Foundation of Korea (NRF) funded in part by the Ministry of Education (2010-0020163) and by the Ministry of Science, ICT \& Future Planning (NRF-2016R1C1B2014826).

\section{REFERENCES}

1) Hallpike CS, Cairns H. Observations on the pathology of Ménière's syndrome. J Laryngol Otol 1938;53(10):625-55.

2) Kim KS. Meniere's disease. Res Vestib Sci 2004;3(1):75-87.

3) Committee on Hearing and Equilibrium. Report of Subcommittee on Equilibrium and its Measurement. Meniere's disease: criteria for diagnosis and evaluation of therapy for reporting. Trans Am Acad Ophthalmol Otolaryngol 1972;76(6):1462-4.

4) Committee on Hearing and Equilibrium. Committee on Hearing and Equilibrium guidelines for the diagnosis and evaluation of therapy in Meniere's disease. American Academy of OtolaryngologyHead and Neck Foundation, Inc. Otolaryngol Head Neck Surg 1995; 113(3):181-5.

5) Lopez-Escamez JA, Carey J, Chung WH, Goebel JA, Magnusson $\mathrm{M}$, Mandalà $\mathrm{M}$, et al. [Diagnostic criteria for Menière's disease. Consensus document of the Bárány Society, the Japan Society for Equilibrium Research, the European Academy of Otology and Neurotology (EAONO), the American Academy of OtolaryngologyHead and Neck Surgery (AAO-HNS) and the Korean Balance Society]. Acta Otorrinolaringol Esp 2016;67(1):1-7.

6) Pearson BW, Brackmann DE. Committee on Hearing and Equilibrium guidelines for reporting treatment results in Meniere's disease. Otolaryngol Head Neck Surg 1985;93(5):579-81.

7) Meniere P. Meladdie de l'oreille interne offarut les symptomes de la congestion cerebrate apoplecitiforme. Gaz Med Paris 1861;3:88.

8) Politzer A. Uber Laesion des labyrinthes. Arch Ohrenheilk 1867;2: 88-99.

9) Boles R, Rice DH, Hybels R, Work WP. Conservative management of Méniére's disease: furstenberg regimen revisited. Ann Otol Rhinol Laryngol 1975;84(4 Pt 1):513-7.

10) da Costa SS, de Sousa LC, Piza MR. Meniere's disease: overview, epidemiology, and natural history. Otolaryngol Clin North Am 2002; 35(3):455-95.

11) House WF. Subarachnoid shunt for drainage of hydrops. a report of 63 cases. Arch Otolaryngol 1964;79:338-54.

12) Portmann G. Surgical treatment of vertigo by opening of the saccus endolymphaticus. Arch Otolaryngol 1969;89(6):809-15.

13）渡辺行雄: 厚生労働省難治性疲患克服研究事業前庭機能異常に関 する調査研究班: メニエール病診断基準改定にあたって. Equilibrium Res 2009;68(4):218-25.

14）厚生労働省難治性疿患克服研究事業前庭機能異常に関する調査 研究班: メニエール病診療ガイドライン. 金原出版, 東京. 2011.

15）小松崎篤: めまいの診断基準化のための資料. Equilibrium Res 1988; 47:247-8.

16) Schuknecht HF. Pathophysiology of Meniere's disease. Otolaryngol Clin North Am 1975;8(2):507-14.

17) Dohlmann GF. On the mechanism of the Menière attack. Arch Otorhinolaryngol 1976;212(4):301-7.

18) Choi JS, Shin SH, Choi H, Kim KS. A case of Lermoyez' syndrome. Res Vestib Sci 2010;9(3):118-20. 


\section{정답 및 해설}

답 (4)

해 설 후비공폐쇄(choanal atresia)는 출생아 8000명당 1명꼴로 나타나는 드문 선천성 질환으로 남녀비는 2:1 정도로 여아에 많 으며 일측성이 양측성보다 2배 정도 많다. 좌측보다 우측에 흔하며 인종 간 차이는 없다. 후비공폐쇄 환자의 $50 \%$ 가량에 서는 Treacher-Collins 증후군, 새궁기형, 심장 및 위장관기형 등 다른 선천성 기형을 동반하며, 특히 양측성인 경우에 선 천성 기형의 동반이 흔하다. 폐쇄 양상에 따라 골성, 막성, 혼합성 폐쇄로 분류할 수 있으며 $90 \%$ 가 골성 폐쇄이다. 치료는 폐쇄의 정도, 환자의 연령 및 동반 기형의 유무에 따라 달라지며 양측성의 경우 근본적인 수술 치료에 앞서 McGovern's nipple이나 구인강 튜브로 구강기도를 확보하고 튜브를 통해 적절한 영양을 공급해야 하며, 수술은 생후 1년경에 시행한다. 일측성인 경우 구개의 성장이 충분히 이루어진 뒤에 수술을 시행하는 것이 좋다. 